Research, part of a Special Feature on Mental Models

\title{
Urban Ethnohydrology: Cultural Knowledge of Water Quality and Water Management in a Desert City
}

\author{
Meredith Gartin ${ }^{1}$, Beatrice Crona ${ }^{2,3}$, Amber Wutich ${ }^{1,3}$, and Paul Westerhoff ${ }^{4}$
}

\begin{abstract}
Popular concern over water quality has important implications for public water management because it can both empower water utilities to improve service but also limit their ability to make changes. In the desert city of Phoenix, Arizona, obtaining sufficient high-quality water resources for a growing urban population poses a major challenge. Decision makers and urban hydrologists are aware of these challenges to water sustainability but the range of acceptable policy and management options available to them is constrained by public opinion. Therefore, this study examines cultural models of water quality and water management, termed ethnohydrology, among urban residents. The study yields three key findings. First, urban residents appear to have a shared model of ethnohydrology which holds that a) there are significant water quality risks associated with low financial investments in city-wide water treatment and the desert location of Phoenix, and b) government monitoring and management combined with household-level water treatment can yield water of an acceptable quality. Second, people with high incomes are more likely to engage in expensive water filtration activities and to agree with the cultural ethnohydrology model found. Third, people living in communities that are highly concerned about water quality are less likely to share high agreement around ethnohydrology. The results have implications for water policy making and planning, particularly in disadvantaged and vulnerable communities where water quality is perceived to be low.
\end{abstract}

Key Words: cultural consensus; cultural model; freelist; perceptions; Phoenix; urban; water quality

\section{INTRODUCTION}

Contemporary urban water governance is characterized by increasing complexity, in terms of environmental change, socioeconomic conditions, population growth, and regulatory oversight. Urban hydrology is particularly challenging because water management is so closely intertwined with the needs and concerns of diverse stakeholders such as residential populations, businesses, and environmental groups (Niemcyznowicz 1999). In the desert city of Phoenix, Arizona, obtaining sufficient high-quality water resources for a growing urban population poses a major challenge. Decision makers and urban hydrologists are aware of these challenges to water sustainability but the range of acceptable policy and management options available to them is constrained by public opinion. Given the strong human component in urban hydrology, decision makers must be aware of and responsive to urban residents' cultural knowledge, i.e., beliefs and perceptions, of water quality and water management because this affects political opinion (Niemcyznowicz 1999). Simultaneously, research suggests that ecological understanding among urbanites is often relatively poor (Cox 2005, McDaniel and Alley 2005, Reyes-García et al. 2005, 2007, Gober 2006, Barthel 2008), but few studies have focused on water specifically.

We investigate locally situated, cultural knowledge of water, which we term ethnohydrology, in the fastgrowing desert city of Phoenix. We use a cultural consensus modeling approach to assess urban ethnohydrology, with a particular emphasis on water quality and water management. The paper has two goals: 1) to examine the extent to which ethnohydrology is shared across Phoenix

\footnotetext{
${ }^{1}$ School of Human Evolution and Social Change, Arizona State University, ${ }^{2}$ Stockholm Resilience Center, Stockholm University, Sweden, ${ }^{3}$ Center for the Study of Institutional Diversity, Arizona State University, ${ }^{4}$ Department of Civil, Environmental and Sustainable Engineering, Ira A. Fulton School of Engineering, Arizona State University
} 
neighborhoods; and 2) to explore the factors that shape how cultural agreement around ethnohydrology is distributed among residents. The scientific models that underpin hydrological decision making draw on specialized knowledge from hydrology and engineering. This knowledge is not readily accessible to the general public and consequently important hydroecological elements may not be reflected in ethnohydrology models of urbanites. We examine how ethnohydrology compares with scientific knowledge and discuss possible implications of our findings for policy and research.

\section{APPROACH}

Cultural knowledge is defined as a set of learned and shared beliefs, perceptions, and understandings of a group (Garro 1986, Romney et al. 1986, Weller 2007, Weller et al. 1986). Central to this definition is a cultural domain, i.e., a set of cognitively related knowledge items that are all of the same type, such as "fruit" (Furlow 2003). Implicit in this notion is the idea that domain membership is not solely determined by the individual respondent, but it exists "out there" either in the language, culture, or reality. Ethnoecological knowledge is the subset of cultural knowledge that people use to understand, navigate, and utilize local environmental resources (Gragson and Blount 1999, Nazarea 1999). Ethnoecologists have focused on domains such as ethnobiology (e.g., Berlin 1992), ethnobotany (e.g., Turner and Bell 1971), ethnozoology (e.g., Boster and Johnson 1989, Sillitoe 2002), and ethnoentomology (e.g., Costa-Neto 2002). Ethnohydrology was first identified as an area of inquiry in Back's (1981) historical study on Native American understandings of water. Later, Gelles $(1998,2000)$ and Sherbondy $(1982,1992)$ suggested that ethnohydrology can be organized along two dimensions: spiritual and ritual water beliefs, and technical knowledge of water quality and management. We focus on the latter based on its relevance for urban water issues.

We use cultural consensus, a core method in ethnoecology, to study urban ethnohydrology. Cultural consensus analysis (CCA) is commonly used to measure the degree to which cultural knowledge is shared in a cultural domain (Garro 1986, Romney et al.1986, Weller et al. 1986, Romney 1999). CCA rests on three major assumptions: 1) there exists a certain shared knowledge base, i.e., a "cultural model" and a "culturally correct" set of knowledge related to the domain; 2) people give their answers independently from one another; and 3) the probability that a person will provide correct information about the domain reflects the individual's level of knowledge, expertise, or "cultural competence" (Romney et al. 1986, Furlow 2003). CCA is especially productive for ethnoecology because it enables researchers to determine what people know about their local environment and what factors shape agreement around ethnoecological knowledge. Key findings from this research reveal the influence of urbanization (Ross 2002, Reyes-García et al. 2005) and market integration (Reyes-García et al. 2007) on ethnobiological knowledge. Recent findings have also demonstrated the importance of epistemological orientations on ecological reasoning and conflicts (Bang et al. 2007, Ross et al. 2007).

For our study, prior research provided little guidance regarding factors that might influence agreement around cultural models of ethnohydrology, i.e., cultural competence. Thus, we selected explanatory variables based on their known association with water quality concern. We included the following respondent characteristics: 1) neighborhood concern about water quality, 2) length of residency, 3) income level, 4) racial minority status, and 5) use of water filters. First, knowledge is constructed through participation in activities and interaction with others (D'Andrade 1987, 1995, Weller 1987). Our past ethnographic research in Phoenix suggested that, in neighborhoods with high concern about water quality, people frequently speculated about the causes and consequences of poor water quality. Based on our observations, in which concern, doubt, and speculation appeared to undermine agreement, we hypothesize that people living in high-concern neighborhoods will have lower cultural competence. Second, there is some evidence that older people and those with greater length of residency in a community have more confidence in water safety (Jones et al. 2005). We therefore hypothesize that length of residency will be positively correlated with cultural competence. Third and fourth, research in Arizona indicates that minorities and people with low incomes are more susceptible to environmental injustices (Bolin et al. 2005) and are more likely to be distrustful of water quality (Williams and Florez 2002). Following our assumption about concern and doubt undermining agreement, we hypothesize that minority status and low income will be negatively correlated with cultural competence. Fifth, individual water 
treatment strategies, such as using water filters, are important indicators of residents' perceptions of taste and water quality (York et al. 2011). We hypothesize that people who use water filters will be more likely to agree about water quality and have higher cultural competence.

Beyond the social patterning of cultural knowledge, many scholars are interested in the practical significance of ethnoecological research (Hunn 1982, Gragson and Blount 1999). Several studies have used cultural consensus to rigorously compare the knowledge of local and scientific experts. Most of these have shown significant divergences between locals and scientists (e.g., Medin et al. 1997, Miller et al. 2004, Johnson and Griffith 2010). Although many scholars emphasize the added value of locally embedded ethnoecological knowledge (e.g., Berlin et al. 1999), a few have suggested that flawed local understandings of human-environment interactions can pose a threat to sustainable management. For example, McDaniel and Alley (2005) suggest urban residents may translate a lack of ecological understanding into support for public policies that promote population or economic growth and further degrade a resource on which they depend. Regarding urban water management, Jones et al. (2005) show that people often make decisions about their water based on incomplete or inappropriate information and McDaniels et al. (1997) found that poor perception of risk or controllability by the public can lead to communal inaction regarding a hazard even if strategies for risk management have been identified. We therefore argue that in an urban context, it is important to discuss how ethnohydrology might align with scientific evidence on the topic of water quality and water management. We do this by examining the ethnohydrology model in light of scientifically published information.

\section{METHODS}

\section{Study setting}

As research predicts a warmer and drier future in the southwestern U.S. (Ellis et al. 2008), obtaining water resources for growing urban populations will be a major challenge. The city of Phoenix, Arizona, located in the Sonoran desert, is the U.S.'s fifth largest city and is projected to grow another $60 \%$ by 2030 (City of Phoenix 2010). The combination of rapid population growth and desert environment makes water management a challenging task.

New residents come to Phoenix to enjoy lifestyles that involve swimming pools, golf courses, and other water consumptive amenities (Sokol 2005, Sterns 2005, Gober 2006). Phoenix water decision makers are sensitive to the city's water challenges (Wutich et al. 2010), but the range of acceptable policy and management options available to them is constrained by public opinion, which in turn depends on how residents and other constituencies perceive causes and solutions related to water issues. Although some residents express concern that the city is incapable of sustaining current and projected levels of water consumption, garnering political support for policies that limit growth or promote water conservation measures has been difficult (Harlan et al. 2007).

Currently, Phoenix's water supply relies on a highly dynamic and complex hydrological management system that incorporates four major water sources: surface water from the Salt and Verde Rivers, ground water, Colorado River water through the Central Arizona Project, and reclaimed water, for nonpotable uses only (Gober et al. 2010). The availability of each of these supply sources is governed by unique hydrologic, legal, and institutional systems and therefore is not very transparent to local residents.

\section{Site selection}

This study follows up the Phoenix Area Social Survey II (PASS II), a 40-neighborhood survey conducted in greater Phoenix. Results from PASS II indicated that more than $40 \%$ of survey respondents were concerned about water quality (Harlan et al. 2007). We selected four neighborhoods in south and central Phoenix as the sites for data collection, two with average high and low water quality concern, respectively. We chose this design because we aimed to capture and compare cultural beliefs across neighborhoods. To ensure that actual water quality did not vary, we selected neighborhoods that share the same water provider, and thus similar water quality. 


\section{Study design}

The study design is an exploratory/explanatory case study conducted in two phases. In Phase I, we collected freelist data that formed the basis for inductive item development and cultural consensus survey construction. In Phase II, we collected survey data and conducted cultural consensus and related analyses.

\section{Phase I: survey development}

Freelisting is a commonly used method for identifying items in a cultural domain and developing cultural consensus items inductively (e.g., Reyes-García et al 2004). In freelisting, respondents are asked to list every item they can think of in a given cultural domain. In this study we used successive freelisting (Ryan et al. 2000). This method was developed to overcome the limitations of standard freelist data by linking multiple lists together. As such it allows for analysis of how lists are related and the rules informants use to order listed items. This was important because we aimed to capture how respondents conceptualized the relationship between water quality, the factors affecting it, and available solutions. Our first freelist task was to ask respondents to describe their tap water quality. For each item listed, we then asked what caused the water to have the quality named, followed by what could be done to improve or safeguard water quality.

Successive freelists were collected with a purposive sample of 131 residents from our four focal neighborhoods, i.e., approximately 30 per neighborhood. Trained field assistants recruited respondents from public spaces, e.g., sidewalks, parks, shopping centers, in each neighborhood. A total of 233 water quality descriptors were elicited and entered into a descriptor-by-respondent matrix. Descriptors were reviewed; similar items were grouped and sorted according to their frequency of mention. A scree plot identified the most commonly used water quality descriptors. These 32 most frequently mentioned descriptors and their associated causes and solutions were used as the basis for constructing 130 cultural consensus statements.

Starting with the 130 statements describing water quality, causes, and solutions, the team narrowed the list to 50 yes/no survey items. Survey items were selected for inclusion in the final survey based on their frequency of mention, clarity of reasoning, and relevance to local water concerns. Twenty-five items regarding causes of water quality issues and 25 items regarding solutions to water quality issues were developed. All items were designed to maintain a balance between positive and negative wording. These items were extensively pretested to ensure that the instrument was clear and comprehensible to the study population.

\section{Phase II: survey research}

The final survey contained three modules: 1) cultural consensus questions; 2) questions about water quality concerns, tap water use, and water filter use; and 3) general demographics such as age, gender, racial minority status, income, and length of residency. Trained interviewers approached all households in three of the neighborhoods and, in the fourth neighborhood, recruited respondents from public spaces because of the large number of gated households. We canvassed each neighborhood completely multiple times before the target of 30 interviews was met. Survey data was collected from 113 respondents. To conduct a consensus analysis in which true agreement is moderate $(r=0.40)$ with 95 percent of cultural items correctly classified at 0.99 confidence level, a sample size of $n=49$ is required (Romney et al. 1986); our sample meets this criteria.

ANTHROPAC 4.983 was used to conduct formal cultural consensus analysis (Borgatti 2002). We used three main metrics to analyze the model. First, a measure of the overall fit, or a ratio between the individual loadings on the first and second factors, was used to determine whether or not consensus exists. A ratio greater than three between the eigenvalues of the first two factors indicates a unidimensional solution and thus that a shared cultural model exists (see Curry et al. 2002, Weller and Baer 2002). Second, we considered "culturally correct responses" to be those for which high consensus about the correct response exists, i.e., $\geq$ $60 \%$ of respondents agree. We report only culturally correct responses, and omit discussion of items for which there was less agreement. Third, the model yielded a "competence score" for each informant which refers to the proportion of culturally correct answers given by each respondent (corrected for guessing).

Building on this analysis, we then conducted a regression analysis to explore the association 
between respondents' individual characteristics and their cultural competency scores (dependent variable). Independent variables were operationalized as follows: 1) neighborhood concern about water quality $(1=$ lives in a high concern neighborhood; $0=$ lives in a low concern neighborhood);2) tenure, i.e., number of years living in Phoenix; 3 ) household income ( $1=\geq \$ 100,000$, i.e., upper quintile of U.S. incomes; $0=<\$ 100,000)$; 4) racial minority status $(1=$ African American or American Indian; $0=$ all others); and 5) use of water filters ( $1=$ use filter; $0=$ no filter). Statistical analyses were performed in SPSS 16.0. We tested for multicollinearity and found no associations ( $>0.7$ ) between the independent variables or tolerance values $(<0.1)$, nor any evidence of non-normality or heteroskedasticity.

\section{RESULTS AND DISCUSSION}

\section{Cultural consensus analysis}

A ratio of 3.34 between loadings on the first and second factor was found, which meets the criterion for existence of a formal, cultural model. We explored the data for subcultures of consensus by dividing it into subsamples based on socioeconomic status (above or below \$100,000), neighborhood location (high vs. low concern), and by separating causes from solutions, but none of these yielded a ratio greater than three. We therefore conclude that sampled residents share one ethnohydrology model and we present a detailed analysis of it below. Percentage of respondent agreement is given in parentheses.

\section{Causes of water quality}

During freelisting, we found that respondents used predominately negative terms, such as dirty, hard, unsafe, nasty, and tastes bad or funny, to describe Phoenix water. In the consensus analysis, we found high agreement around a number of the causes of water quality issues. First, a range of contaminants, specifically, metals (80\%), minerals (79\%), bacteria $(73 \%)$, algae $(68 \%)$, and garbage thrown in water transport canals $(65 \%)$, are identified as causes of negative water quality.

Second, the cultural model showed that living in a desert caused some aspects of poor water quality. For instance, there was agreement that living in the desert causes warm water to come out of the tap
(79\%) and that warm water temperature causes algal growth in the water $(81 \%)$. There was consensus that dust storms, which are common in the Sonoran desert, cause dirty water to come out of the tap (68\%). There was also agreement that water scarcity causes people to settle for a lower level of water quality $(65 \%)$.

Third, we found consensus around the desirability of specific water sources. For instance, the cultural model indicates Colorado River $(74 \%)$ and Verde River $(63 \%)$ as good sources of water, although there was no clear consensus around water from the Salt River. Paradoxically, the cultural model indicated that wells are a good source of water $(75 \%)$ but that groundwater is not $(69 \%)$. Additionally, treated waste water is not considered to be a good source of tap water $(73 \%)$.

Fourth, the cultural model indicated that some aspects of water treatment and distribution systems are responsible for poor water quality. There was strong consensus that old pipes negatively impact water quality $(81 \%)$. Additionally, the cultural model indicates that chemicals added to treat water quality cause it to "have a funny taste" $(81 \%)$ and worsens the water's taste $(75 \%)$.

Fifth, the cost of water plays an important role in determining the desirability of water. The cultural model shows that residents' willingness to pay higher prices for water does affect water quality $(69 \%)$ and that financial investment in water treatment makes water taste good (60\%). Additionally, it shows that low prices, in and of themselves, do not make tap water desirable to drink $(69 \%)$.

Finally, the cultural model clearly indicates the importance of government-based water monitoring to maintain current levels of water quality. There was clear consensus that testing water for bacteria improves its taste $(70 \%)$. Also, there was agreement that monitoring for industrial chemical content makes the water taste good (63\%). Finally, it showed that city testing ensures that tap water quality is "okay" (65\%).

\section{Management of water quality}

Consensus items on solutions dealt with strategies that are or could be adopted to improve current water quality. The cultural model indicated the 
importance of both community and household level management responses to water quality issues. In general, there was consensus around fewer of the items describing water management than the causes of water quality issues.

First, the cultural model clearly indicated that infrastructural and technical solutions are an important part of improving water quality. There was strong consensus that better water treatment plants could improve tap water quality $(91 \%)$ and there was widespread agreement that the city government could process tap water differently to make it taste better (86\%). Beyond water treatment, the model also indicated that replacing old pipes would reduce a metallic taste in the tap water $(86 \%)$.

Second, the cultural model suggested that several aspects of water policy could be adopted to improve water quality. There was clear consensus that the adoption of fines for illegal dumping could improve water quality (75\%). There was also agreement that limiting population growth could increase the safety of water $(60 \%)$. Finally, the model indicated that citizen involvement, in terms of communicating with city government representatives, can improve tap water quality $(72 \%)$.

Third, in addition to community level solutions, the cultural model emphasized the ability of home filtration of water to improve quality. There was wide consensus that a home filtration system makes tap water taste better (87\%). Specifically, the model supported the utility of two kinds of water filtration: water softeners and reverse osmosis. There was clear agreement that water softeners can make tap water less hard $(86 \%)$ and that reverse osmosis improves water quality (76\%). Finally, the model indicated that color can be removed from tap water with a filter $(65 \%)$.

Fourth, there was some consensus around low-cost individual strategies that could be adopted to improve water quality. The cultural model showed that boiling tap water can make it less "nasty" (72\%) and there was consensus that adding powdered drink flavoring, such as Kool-Aid, can improve the taste of tap water (66\%). Furthermore, there was agreement that refrigerating tap water before drinking can improve its taste $(60 \%)$.

\section{Ethnohydrology and scientific explanations: exploring discrepancies}

Given the role that urban residents play in shaping local water policy, it is important to examine how well urban ethnohydrology fits with scientific views of water quality and water management. Cultural knowledge may or may not be an accurate reflection of reality, or in agreement with how science perceives processes underlying human-environmental interactions. Ethnohydrological knowledge relating to old pipes is an example. Pipes do affect tap water quality but not as perceived by residents. As water passes through pipes at high velocity, corrosion materials can shear off. These materials are usually iron based but pose very low, if any, health risk and do not affect taste or odor (Mallevialle and Suffet 1987). Replacing old pipes is therefore one solution to improve tap water quality, but it is unlikely to reduce metallic taste of tap water because this comes from salts, i.e., calcium, magnesium, aluminum, most often associated with the original water source (Whelton et al. 2006, Burlingame et al. 2007).

Another example of how ethnohydrological explanations can differ from scientific ones is the shared perception that living in the desert results in warm tap water, which in turn causes algal growth, thus lowering tap water quality and causing bad taste. The observation that tap water is warmer during hot desert temperatures is accurate because pipes and storage tanks are exposed to warm ambient temperatures. However, algae are removed in the treatment process and warm temperatures do not cause algae to grow in tap water. Instead, algae release organic compounds called metabolites prior to their removal in treatment. These metabolites impose an earthy-musty-moldy taste or odor to water (Mallevialle and Suffet 1987). The human nose is extremely sensitive to these compounds and can detect them at parts per trillion levels $\left(10^{-10} \mathrm{~g} /\right.$ L; Mallevialle and Suffet 1987). This, in combination with an incomplete understanding of the treatment process, is a likely explanation of why respondents perceive algae to be a problem rather than a biophysical reaction that takes place during water treatment processes.

We suggest that because residents interact with the water resource at very localized and contained scales, i.e., through the tap, this decouples them from many of the environmental factors that affect water quality. Such scale effects may explain the divergences between scientific and local knowledge. 
Table 1. Recoded variables and descriptive statistics. Because all variables are binary, \% Sample indicates the percentage of respondents whose answers corresponded to Code $=1$.

\begin{tabular}{|c|c|c|c|c|c|c|}
\hline Variable & Variable description & Coded & $\%$ Sample $=1$ & Range & Mean & $\mathrm{n}$ \\
\hline Neighborhood Concern & Level of Concern & $\begin{array}{l}\text { Low Concern }=0 \\
\text { High Concern }=1\end{array}$ & 0.48 & 1 & -- & 113 \\
\hline Tenure & $\begin{array}{l}\text { Number of years lived in } \\
\text { Phoenix Metropolitan Area }\end{array}$ & Years & -- & 67 & 23.03 & 110 \\
\hline Income Level & Household Income Level & $\begin{array}{l}<\$ 100,000=0 \\
>\$ 100,000=1\end{array}$ & 0.26 & 1 & -- & 90 \\
\hline Minority Status & $\begin{array}{l}\text { African-American or } \\
\text { American Indian }\end{array}$ & $\begin{array}{c}\text { Minority Status=1 } \\
\text { Nonminority }=0\end{array}$ & 0.17 & 1 & -- & 82 \\
\hline Water Filter Use & $\begin{array}{l}\text { Household attached a filter } \\
\text { to a pitcher, faucet, } \\
\text { refrigerator, or piping system }\end{array}$ & $\begin{array}{l}\text { Use of filter }=1 \\
\text { No filter use }=0\end{array}$ & 0.43 & 1 & -- & 113 \\
\hline
\end{tabular}

Scientific knowledge takes into account political, environmental, and socioeconomical processes at a larger scale than is perceived by local residents. Evidence of this is expressed in the cultural model where a focus on pipes, largely local, in-house structures, and different household solutions, such as water filtering and softening systems appear, as salient, cultural knowledge.

\section{Regression analysis}

Ordinary least squares multiple linear regression was used to determine the association between the independent variables and dependent variable (Table 1). The model accounts for $25 \%$ of the variance in cultural consensus scores $(\mathrm{p}<0.005$; Table 2). Ethnohydrology knowledge is a difficult phenomenon to quantify and to our knowledge has never before been measured. We therefore believe the variance explained is reasonable, albeit not high, as a first step in understanding factors affecting cultural competence surrounding water quality and water management. Controlling for other factors, income level and neighborhood concern were significantly associated with respondents' competence scores, whereas tenure, minority status, and filter use were not.
People with lower incomes tended to have lower cultural competencies, i.e., less shared agreement, in the ethnohydrology model than those with higher incomes. As suggested in our hypotheses, we believe this is related to widely recognized issues of environmental injustice. Historically, people with low incomes have had lower quality water service in Phoenix (Bolin et al. 2005) and, as a result, may be more questioning of the shared cultural model. Exploration of the data using T-tests indicate that people who used water filters had a higher income $(\mathrm{t}(87)=3.97, \mathrm{p}<0.0005)$ and had higher cultural consensus scores $(t(109)=2.15, p=0.03)$. In the regression model, however, the relationship between filter use and competency scores disappears when controlling for income. This suggests that income influences both respondents' use of water filters and their knowledge of ethnohydrology. We believe this finding is linked to the issue of scale explored above. Because the ethnohydrology model has such a strong focus on local scale, filters become a natural local strategy to deal with water quality. However, individuals with higher income are better placed to utilize filters to address water quality because of their economic status. We therefore argue that people with higher incomes tend to have high cultural competence at least in part because they agree about the importance 
Table 2. Correlates of individual cultural competency scores.

\begin{tabular}{lcccc}
\hline \hline$N=63, r^{2}=0.25$, Adj. $r^{2}=0.18, F=3.80, p=0.005$ & & & \\
\hline Variable & Beta & Std. Error & Std. Beta & P-Value \\
\hline Constant & 0.372 & 0.052 & & 0.000 \\
Neighborhood Concern & -0.120 & 0.055 & -0.299 & 0.033 \\
Tenure & 0.001 & 0.001 & 0.093 & 0.506 \\
Income Level & 0.161 & 0.061 & 0.346 & 0.011 \\
Minority Status & 0.055 & 0.061 & 0.110 & 0.366 \\
Water Filter Use & 0.008 & 0.054 & 0.020 & 0.880 \\
\hline
\end{tabular}

of adopting costly water improvement strategies such as water filtration.

People who lived in neighborhoods with high concern about local water quality tended to have lower cultural competencies than people living in neighborhoods with low concern about water quality. Our ethnographic experience in Phoenix indicates that there were more rumors, doubt, and speculation about water quality in high-concern neighborhoods. People living in high-concern neighborhoods were more likely to suggest singular, uncommon causes of water quality issues, e.g." "city government cannot be trusted to keep the tap water clean", and management strategies, e.g., "drinking bottled water is a solution for poor quality tap water", thus indicating less confidence in and endorsement of the cultural model. In contrast, where neighborhood concern was low, people were more in agreement about the issues affecting water quality and water management.

\section{CONCLUSIONS AND IMPLICATIONS}

Using a combination of inductive and deductive approaches, this research developed and assessed a cultural model of ethnohydrology in the desert city of Phoenix, Arizona. Following the ethnohydrology framework by Gelles $(1998,2000)$ and Sherbondy $(1982,1992)$ we focused predominately on water quality and water management. Our emphasis on urban ethnohydrology has particular relevance for contemporary water management challenges and the study yields three key findings. First, urban residents appear to have a shared model of ethnohydrology which holds that a) there are significant water quality risks associated with low financial investments in city-wide water treatment and the desert location of Phoenix; and b) government monitoring and management combined with household-level water treatment can yield water of an acceptable quality. Second, people with high incomes are more likely to engage in expensive water filtration activities and to agree with the cultural ethnohydrology model found. Third, people living in communities that are highly concerned about water quality are less likely to share high agreement around ethnohydrology. These results have implications for water policy making and planning, particularly in disadvantaged and vulnerable communities where water quality is perceived to be low.

In most industrialized cities, the main interaction for urban residents with their water resource is at a very local scale, through the tap. Consequently, it appears that things that are directly observable such as infrastructure and municipal treatment facilities come to play a stronger role in their conceptualization of the water resource than other environmental factors. Incomplete understanding of 
the ecological and political processes that also underlie urban water delivery is thus likely to characterize urban ethnohydrology, not just in Phoenix but also cross-culturally. Divergent perceptions between decision makers, hydrologists, and urban residents are an issue of concern if public perceptions limit acceptance of long-term sustainable policy change. This paper discusses some examples of divergence between urban ethnohydrology models and scientific evidence of water quality. In our case, most are linked to concern for water quality as a result of a very localized perspective and incomplete understanding of environmental factors affecting water quality. In such cases, outreach and arenas for community participation in dialogues around water issues could play a particularly important role in reducing potentially unnecessary concern for quality and safety surrounding tap water.

The study makes several recommendations for the use of ethnohydrology research to further our understanding of urban resident-environment interactions. First, ethnohydrology knowledge could be examined between different stakeholder groups and compared with scientists and hydrologists to systematically assess the extent that scientific and cultural discrepancies exist. Second, urbanization and market integration have been shown to shape ethnoecological knowledge (ReyesGarcía et al. 2005, 2007, Ross 2002) but we suggest that marketing by commercial interests, such as for water filters, softeners, and other household type solutions, may also impact urban ethnohydrology. This should be explored in more detail. Third, although our model made no mention of conservation strategies, sustainable management might be a fruitful topic for comparative research conducted with populations living in different urban-ecological environments. Such research has the potential to expose a broad and diverse range of local strategies for conserving and ensuring the sustainability of local water resources.

Responses to this article can be read online at: http://www.ecologyandsociety.org/voll5/iss4/art36/ responses/

\section{Acknowledgments:}

We thank all the participants who contributed with their time to this study. The work was funded by the National Science Foundation (NSF) Grant No. SES-0345945 Decision Center for a Desert City (DCDC), NSF grant number DEB-0423704 Central Arizona-Phoenix Long-Term Ecological Research, the Arizona State University Late Lessons from Early History program, and The Swedish Research Council (Vetenskapsrådet). Any opinions, findings and conclusions, or recommendations expressed in this material are those of the author(s) and do not necessarily reflect the views of the funding agencies.

\section{LITERATURE CITED}

Back, W. 1981. Hydromythology and ethnohydrology in the New World. Water Resource Research 17:257-287.

Bang, M., D. L. Medin, and S. Atran. 2007. Cultural mosaics and mental models of nature. Proceedings of the National Academy of Sciences 104(25):13868-13874.

Barthel, S. 2008. Recalling urban nature - linking city people to ecosystem services. Dissertation. Stockholm University, Stockholm, Sweden.

Berlin, B. 1992. Ethnobiological classifications: principles of categorization of plants and animals in traditional societies. Princeton University Press, Princeton, New Jersey, USA.

Berlin, B., E. Berlin, J. Ugalde, L. Barrios, D. Puett, R. Nash, and M. Gonzalez-Espinosa. 1999. The Maya ICBG: drug discovery, medical ethnobiology, and alternative forms of economic development in the Highland Maya region of Chiapas, Mexico. Pharmaceutical Biology 37:127-144.

Bolin, R., S. Grineski, and T. Collins. 2005. Geography of despair: environmental racism and the making of South Phoenix, Arizona, USA. Human Ecology Review 12(2):156-168.

Borgatti, S. P. 2002. Anthropac 4.0. Analytic Technologies, Columbia, South Carolina, USA. 
Boster, J. S., and J. C. Johnson. 1989. Form or function: a comparison of expert and novice judgments of similarity among fish. American Anthropologist 91(4):866-889.

Burlingame, G. A., A. M. Dietrich, and A. J. Whelton. 2007. Understanding the basics of tap water taste. Journal American Water Works Association 99(5):100.

City of Phoenix. 2010. Community trends and profile. [online] URL: http://phoenix.gov/CITYGOV/ stats.html.

Costa-Neto, E. 2002. The use of insects in folk medicine in the State of Bahia, North Eastern Brazil, with notes on insects reported elsewhere in Brazilian folk medicine. Human Ecology 30 (2):245-263.

Cox, P. 2005. The restless urban landscape: economic and socio-cultural change and the transformation of metropolitan Washington DC. Pages 281-292 in R. N. Fyfe and T. J. Kenny, editors. The urban geography reader. Routledge, New York, New York, USA.

Curry, M., H. Mathews, H. Daniel, J. Johnson, and C. Mansfield. 2002. Beliefs about and responses to childhood ear infections: a study of parents in Eastern North Carolina. Social Science and Medicine 54:1153-1165.

D'Andrade, R. G. 1987. Modal responses and cultural expertise. American Behavioral Scientist 31(2):194-202.

D'Andrade, R. G. 1995. The development of cognitive anthropology. Cambridge University Press, Cambridge, UK.

Ellis, A. W., T. W. Hawkins, R. C. Balling Jr., and P. Gober. 2008. Estimating future runoff levels for a semi-arid fluvial system in central Arizona. Climate Research 35(3):227-239.

Furlow, C. A. 2003. Comparing indicators of knowledge within and between cultural domains. Field Methods 15:51-62.

Garro, L. C. 1986. Intracultural variation in folk medical knowledge: a comparison between curers and noncurers. American Anthropologist 88:351-370.
Gelles, P. 1998. Competing cultural logics: state and 'indigenous' models in conflict. Pages 256-278 in R. Boelens, G. Dávila, R. Menchú, editors. Searching for equity: conceptions of justice and equity in peasant irrigation. Van Gorcum, Assen, The Netherlands.

Gelles, P. 2000. Water and power in highland Peru: the cultural politics of irrigation and development. Rutgers University Press, Piscataway, New Jersey, USA.

Gober, P. 2006. Metropolitan Phoenix: place making and community building in the desert. University of Pennsylvania Press, Philadelphia, Pennsylvania, USA.

Gober, P., C. Kirkwood, R. Balling, A. Ellis, and S. Deitrick. 2010. Water planning under climatic uncertainty in Phoenix: why we need a new paradigm. Annals of the Association of American Geographers 100(2):356-372.

Gragson, T., and B. Blount, editors. 1999. Ethnoecology: knowledge, resources and rights. University of Georgia Press, Athens, Georgia, USA.

Harlan, S. L., M. Budruk, A. Gustafson, K. Larson, D. Ruddell, V. K. Smith, S. Yabiku, and A. Wutich. 2007. Phoenix area social survey 2006 highlights: community and environment in a desert metropolis. Central Arizona - Phoenix Long-Term Ecological Research Project, No. 4. Global Institute of Sustainability, Arizona State University, Phoenix, Arizona, USA.

Hunn, E. 1982. The utilitarian factor in folk biological classification. American Anthropologist 84(4):830-847.

Johnson, J., and D. Griffith. 2010. Finding common ground in the commons: intracultural variation in users' conceptions of coastal fisheries issues. Society and Natural Resources 23 (9):837-855.

Jones, A. Q., C. E. Dewey, K. Doré, S. E. Majowicz, S. A. McEwen, D. Waltner-Toews, S. J. Henson, and E. Mathews. 2005. Public perception of drinking water from private water supplies: focus group analysis. BMC Public Health 5:129. 
Mallevialle, J., and I. H. Suffet. 1987. Identification and treatment of tastes and odors in drinking water. American Water Works Association Research Foundation, Denver, Colorado, USA.

McDaniel, J., and K. D. Alley. 2005. Connecting local environmental knowledge and land use practices: a human ecosystem approach to urbanization in West Georgia. Urban Ecosystems 8:23-38.

McDaniels, T. L., L. J. Axelrod, N. S. Cavanagh, and P. Slovic. 1997. Perception of ecological risk to water environments. Risk Analysis 17 (3):341-352.

Medin, D. L., E. B. Lynch., and J. D. Coley. 1997. Categorization and reasoning among tree experts: Do all roads lead to Rome? Cognitive Psychology 32:49-96.

Miller, M. L., J. Kaneko, P. Bartram, J. Marks, and D. D. Brewer. 2004. Cultural consensus analysis and environmental anthropology: yellowfin tuna fishery management in Hawaii. Cross-Cultural Research 38(3):289-314.

Nazarea, V., editor. 1999. Ethnoecology: situated knowledge/located lives. University of Arizona Press, Tucson, Arizona, USA.

Niemcyznowicz, J. 1999. Urban hydrology and water management - present and future challenges. Urban Water 1:1-14.

Reyes-García, V., E. Byron, V. Vadez, R. Godoy, L. Apaza, E. Pérez Limache, W. Leonard, and D. Wilkie. 2004. Measuring culture as shared knowledge: Do test types matter? Data from Tsimane' Amerindians, Bolivia. Field Methods 16 (2):135-156.

Reyes-García, V., V. Vadez, E. Byron, L. Apaza, W. Leonard, E. Perez, and D. Wilkie. 2005. Market economy and the loss of folk knowledge of plant uses: estimates from the Tsimane' of the Bolivian Amazon. Current Anthropology 46 (4):651-656.

Reyes-García, V., V. Vadez, T. Huanca, W. Leonard, and T. McDade. 2007. Economic development and local ecological knowledge: a deadlock? Data from a native Amazonian society. Human Ecology 35(3):371-377.
Romney, A. K. 1999. Culture consensus as a statistical model. Current Anthropology 40:S103S115.

Romney, A. K., S. C. Weller, and W. H. Batchelder. 1986. Culture as consensus: a theory of culture and informant accuracy. American Anthropologist 88:313-338.

Ross, N. 2002. Cognitive aspects of intergenerational change: mental models, cultural change and environmental behavior among the Lacandon Maya of Southern Mexico. Human Organization 61 (2):125-137.

Ross, N., D. Medin, and D. Cox. 2007. Epistemological models and culture conflict: Menominee and Euro-American hunters in Wisconsin. Ethos 35(4):478-515.

Ryan, G. W., J. M. Nolan, and P. S. Yoder. 2000. Successive free listing: using multiple free lists to generate explanatory models. Field Methods 12 (2):83-107.

Sherbondy, J. 1982. El regadío, los lagos y los mitos de origen. Allpanchis 20:3-32.

Sherbondy, J. 1992. Water ideology in Inca ethnogenesis. Pages 46-66 in R. Dover, K. Seibold, and J. McDowell, editors. Andean cosmologies through time: persistence and emergence. Indiana University Press, Bloomington, Indiana, USA.

Sillitoe, P. 2002. Contested knowledge, contingent classification: animals in the highlands of Papua New Guinea. American Anthropologist 104 (4):1162-1171.

Sokol, M. 2005. Reclaiming the city: water and the urban landscape in Phoenix and Las Vegas. Journal of the West 44(3):52-61.

Sterns, J. 2005. Desert tourism meccas thrive: cities play up best features to woo visitors. Arizona Republic, 29 May 2005:5 [online] URL: http://www .azcentral.com/arizonarepublic/news/articles/0529rivalsmain0.html?\&wired.

Turner, N., and M. Bell. 1971. The ethnobotany of the Coast Salish Indians of Vancouver Island. Economic Botany 25(1):63-104. 
Weller, S. C. 1987. Shared knowledge, intracultural variation, and knowledge aggregation. American Behavioral Scientist 31(2):178-193.

Weller, S. C. 2007. Cultural consensus theory: applications and frequently asked questions. Field Methods 19(4):339-368.

Weller, S. C., and R. D. Baer. 2002. Measuring within- and between-group agreement: identifying the proportion of shared and unique beliefs across samples. Field Methods 14:6-25.

Weller, S. C., A. K. Romney, and D. P. Orr. 1986. The myth of a sub-culture of corporal punishment. Human Organization 46(1):39-47.

Whelton, A. J., A. M. Dietrich, D. L. Gallagher, and J. A. Roberson. 2006. Using customer feedback for improved water quality and infrastructure monitoring. Journal American Water Works Association 99(11):62.

Williams, B. L., and Y. Florez. 2002. Do Mexican Americans perceive environmental issues differently than Caucasians: a study of cross-ethnic variation in perceptions related to water in Tucson. Environmental Health Perspectives 110(2):303-310.

Wutich, A, T. Lant, D. D. White, K. L. Larson, and M. Gartin. 2010. Comparing focus groups and individual responses on sensitive topics: a study of water decision makers in a desert city. Field Methods 22(1):88-110.

York, A., A. Barnett, A. Wutich, and B. Crona. 2011. Tap or bottled? A study of local environmental concern. Water International, in press. 